\title{
Body Mass Index, Obstructive Sleep Apnea, and Outcomes of Catheter Ablation of Atrial Fibrillation
}

\author{
KRIT JONGNARANGSIN, M.D., AMAN CHUGH, M.D., ERIC GOOD, D.O., \\ SIDDHARTH MUKERJI, M.D., SUJOYA DEY, M.D., THOMAS CRAWFORD, M.D., \\ JEAN F. SARRAZIN, M.D., MICHAEL KUHNE, M.D., NAGIB CHALFOUN, M.D., \\ DARRYL WELLS, M.D., WARANGKNA BOONYAPISIT, M.D., FRANK PELOSI, JR., M.D., \\ FRANK BOGUN, M.D., FRED MORADY, M.D., and HAKAN ORAL, M.D.
}

From the Division of Cardiovascular Medicine, University of Michigan, Ann Arbor, Michigan, USA

\begin{abstract}
Atrial Fibrillation and Obstructive Sleep Apnea. Background: Obesity and obstructive sleep apnea (OSA) are associated with atrial fibrillation (AF). The effects of a large body mass index (BMI) and OSA on the results of radiofrequency catheter ablation (RFA) of AF are unclear.

Objective: To evaluate the effect of BMI and OSA on the efficacy of RFA for AF.

Methods: RFA was performed in 324 consecutive patients (mean age $=57 \pm 11$ years) with paroxysmal (234) or chronic (90) AF. OSA was diagnosed by polysomnography in 32 of 324 patients (10\%) prior to ablation. Among the 324 patients, $18 \%$ had a normal BMI $\left(<25 \mathrm{~kg} / \mathrm{m}^{2}\right), 39 \%$ were overweight $($ BMI $\geq$ $25 \mathrm{~kg} / \mathrm{m}^{2}$ and $\left.<30 \mathrm{~kg} / \mathrm{m}^{2}\right)$, and $43 \%$ were obese $\left(\geq 30 \mathrm{~kg} / \mathrm{m}^{2}\right)$. RFA was performed to eliminate complex fractionated atrial electrograms (CFAE) in the pulmonary vein antrum and left atrium.

Results: At $7 \pm 4$ months after a single ablation procedure, $63 \%$ of patients without OSA and $41 \%$ with OSA were free from recurrent AF without antiarrhythmic drug therapy $(P=0.02)$. Multivariate analysis including variables of age, gender, type and duration of AF, OSA, BMI, left atrial size, ejection fraction, and hypertension demonstrated that OSA was the strongest predictor of recurrent $A F(O R=3.04,95 \%$ CI: 1.11-8.32, $P=0.03$ ). There was no association between $B M I$ and freedom from recurrent $A F$. A serious complication occurred in 3 of 324 patients, with no relationship to BMI.

Conclusions: OSA is a predictor of recurrent AF after RFA independent of its association with BMI and left atrial size. Obesity does not appear to affect outcomes after radiofrequency catheter ablation of AF. (J Cardiovasc Electrophysiol, Vol. 19, pp. 668-672, July 2008)
\end{abstract}

atrial fibrillation, catheter ablation, obstructive sleep apnea, body mass index

\section{Introduction}

Obesity has been shown to be a modifiable risk factor for atrial fibrillation (AF) mediated by left atrial dilatation. ${ }^{1}$ Obesity is also a predictor of OSA. ${ }^{2}$ Previous studies have reported a strong association between OSA and $\mathrm{AF}^{3-5} \mathrm{An}$ increased risk of stroke and death in patients with $\mathrm{OSA}^{5}$ may be due to a higher prevalence of $\mathrm{AF}^{4}$

A prior study demonstrated that AF is more likely to recur after cardioversion in patients with than without OSA. ${ }^{3}$ However, the relationship between OSA and BMI to the outcomes of catheter ablation of AF have not been described. The purpose of this study was to determine the effects of BMI and OSA on the clinical efficacy of radiofrequency catheter ablation of AF.

Dr. Oral received research grant support from St. Jude Medical Inc. He is a founder and equity owner of Ablation Frontiers.

Address for correspondence: Krit Jongnarangsin, M.D., Division of Cardiovascular Medicine, 1500 E. Medical Center Drive, VAMC 111A, Box 2399 , Ann Arbor, MI 48109, USA. Fax: 734-845-3270; E-mail: kritj@umich.edu

Manuscript received 13 November 2007; Revised manuscript received 4 December 2007; Accepted for publication 17 December 2007.

doi: $10.1111 / \mathrm{j} .1540-8167.2008 .01118 . \mathrm{x}$
Methods

\section{Study Subjects}

The subjects of this study were 324 consecutive patients who underwent radiofrequency catheter ablation of AF at the University of Michigan from July 2005 to June 2006. All patients underwent ablation procedure using the same ablation strategy. Patients who had a prior ablation procedure for $\mathrm{AF}$ were excluded from this study. There were 246 men and 78 women, and their mean age was $57 \pm 11$ years. The mean left atrial size and left ventricular ejection fraction were $44 \pm 7 \mathrm{~mm}$ and $0.56 \pm 0.09$, respectively. AF was paroxysmal in $234(72 \%)$ and chronic in $90(28 \%)$ patients. The clinical characteristics of the study subjects are described in Table 1.

Among the 324 patients, $32(10 \%)$ were diagnosed as having OSA by polysomnography before the ablation procedure based on previously described criteria. ${ }^{6}$ Among the 32 patients with OSA, 18 (56\%) were receiving therapy with continuous positive airway pressure (CPAP) before and after the ablation procedure. Patients with OSA had a larger left atrial size, lower left ventricular ejection fraction, higher BMI, and more often had hypertension than patients without OSA (Table 2).

Based on BMI, subjects were classified as being normal in weight $\left(<25 \mathrm{~kg} / \mathrm{m}^{2}\right)$, overweight $\left(\geq 25\right.$ and $\left.<30 \mathrm{~kg} / \mathrm{m}^{2}\right)$, or obese $\left(\geq 30 \mathrm{~kg} / \mathrm{m}^{2}\right) .^{7}$ Among the 324 patients, 58 (18\%) had 
TABLE 1

Clinical Characteristics of Study Subjects

\begin{tabular}{lc}
\hline Number of patients & 324 \\
Age (years) & $57 \pm 11$ \\
Gender & \\
$\quad$ Men & $246(76)$ \\
$\quad$ Women & $78(24)$ \\
Left atrial size $(\mathrm{mm})$ & $44 \pm 7$ \\
Left ventricular ejection fraction & $0.56 \pm 0.09$ \\
Paroxysmal atrial fibrillation & $234(72)$ \\
Chronic atrial fibrillation & $90(28)$ \\
Body weight $(\mathrm{kg})$ & $95 \pm 20$ \\
BMI $\left(\mathrm{kg} / \mathrm{m}^{2}\right)$ & \\
$\quad$ Normal $\left(<25 \mathrm{~kg} / \mathrm{m}^{2}\right)$ & $58(18)$ \\
Overweight $\left(\geq 25\right.$ and $\left.<30 \mathrm{~kg} / \mathrm{m}^{2}\right)$ & $126(39)$ \\
$\quad$ Obese $\left(\geq 30 \mathrm{~kg} / \mathrm{m}^{2}\right)$ & $140(43)$ \\
Hypertension & $150(46)$ \\
Coronary artery disease & $34(11)$ \\
\hline Data are shown as ma
\end{tabular}

Data are shown as mean \pm standard deviation. Percent values are shown in the parentheses.

a normal BMI, 126 (39\%) were overweight, and 140 (43\%) were obese (Table 3).

\section{Electrophysiologic Study}

The study protocol was approved by the Institutional Review Board. All patients provided informed consent. An electrophysiologic study was performed in the fasting state. Antiarrhythmic drugs except amiodarone (53 patients) were discontinued at least 4-5 half-lives before the study. Amiodarone was discontinued 6-8 weeks prior to the procedure. Through a femoral vein, a quadripolar catheter (EP Technologies, Mountain View, CA, USA) was positioned in the coronary sinus and used for recording and atrial pacing (clinical stimulator model EP-3, EPMed Systems). After the transseptal puncture, systemic anticoagulation with a target activated clotting time of 350 seconds was achieved with intravenous heparin. A three-dimensional reconstruction of the left atrium and pulmonary veins was created using an electroanatomic mapping system (Carto, Biosense Webster, Diamond Bar, CA, USA). A circular 10-pole catheter (Lasso, Biosense Web-

TABLE 2

Clinical Characteristics of Patients Without and with OSA

\begin{tabular}{lccc}
\hline & No OSA & OSA & \\
& N= 292 & N= 32 & P \\
\hline Age (years) & $57 \pm 11$ & $59 \pm 7$ & 0.35 \\
Gender (Male / Female) & $220 / 72$ & $26 / 6$ & 0.52 \\
Left atrial diameter $(\mathrm{mm})$ & $43 \pm 7$ & $48 \pm 7$ & 0.002 \\
Left ventricular ejection fraction & $0.56 \pm 0.09$ & $0.51 \pm 0.01$ & 0.003 \\
Paroxysmal atrial fibrillation & $211(72)$ & $23(72)$ & 1.000 \\
Chronic atrial fibrillation & $81(28)$ & $9(28)$ & \\
Body weight $(\mathrm{kg})$ & $93 \pm 19$ & $112 \pm 20$ & $<0.001$ \\
BMI $\left(\mathrm{kg} / \mathrm{m}^{2}\right)$ & $29 \pm 6$ & $35 \pm 7$ & $<0.001$ \\
BMI & & & \\
$\quad$ Normal $\left(<25 \mathrm{~kg} / \mathrm{m}^{2}\right)$ & $58(20)$ & 0 & $<0.001$ \\
$\quad$ Overweight $\left(\geq 25\right.$ and $\left.<30 \mathrm{~kg} / \mathrm{m}^{2}\right)$ & $118(40 \%)$ & $8(25 \%)$ & $<0.001$ \\
$\quad$ Obese $\left(>30 \mathrm{~kg} / \mathrm{m}^{2}\right)$ & $116(40 \%)$ & $24(75 \%)$ & $<0.001$ \\
Hypertension & $127(44)$ & $23(72)$ & 0.003 \\
Coronary artery disease & $27(9)$ & $7(22)$ & 0.06 \\
\hline Data are shown as man
\end{tabular}

Data are shown as mean \pm standard deviation. Percent values are shown in the parentheses.
TABLE 3

$\mathrm{BMI}$ and Clinical Characteristics of Patients with AF

\begin{tabular}{|c|c|c|c|c|}
\hline & $\begin{array}{l}\text { Normal } \\
\mathbf{N}=58\end{array}$ & $\begin{array}{l}\text { Overweight } \\
N=126\end{array}$ & $\begin{array}{c}\text { Obese } \\
\mathbf{N}=140\end{array}$ & $\mathbf{P}$ \\
\hline Age (years) & $58 \pm 12$ & $56 \pm 11$ & $58 \pm 9$ & 0.59 \\
\hline Gender (Male/Female) & $40 / 18$ & $108 / 18$ & $98 / 42$ & 0.52 \\
\hline $\begin{array}{l}\text { Left atrial diameter } \\
\quad(\mathrm{mm})\end{array}$ & $40 \pm 7$ & $42 \pm 6$ & $46 \pm 7$ & $<0.001$ \\
\hline $\begin{array}{l}\text { Left ventricular } \\
\text { ejection fraction }\end{array}$ & $0.57 \pm 0.06$ & $0.56 \pm 0.09$ & $0.54 \pm 0.09$ & 0.06 \\
\hline $\begin{array}{l}\text { Paroxysmal atrial } \\
\text { fibrillation }\end{array}$ & $49(85)$ & 97 (77) & $88(63)$ & 0.003 \\
\hline $\begin{array}{l}\text { Chronic atrial } \\
\text { fibrillation }\end{array}$ & $9(15)$ & $29(23)$ & $52(37)$ & \\
\hline OSA & 0 & 8( & $24(17)$ & $<0.001$ \\
\hline BMI & $22 \pm 2$ & $27 \pm 1$ & $36 \pm 5$ & $<0.001$ \\
\hline Hype & $18(31)$ & $50(40)$ & $82(59)$ & $<0.001$ \\
\hline Coronary artery disease & $4(7))$ & $14(11)$ & $16(11)$ & 0.612 \\
\hline
\end{tabular}

Data are shown as mean \pm standard deviation. Percent values are shown in the parentheses. $\mathrm{EF}=$ ejection fraction.

ster) was then inserted in the left atrium and positioned in all pulmonary veins for mapping. Barium sulfate esophageal cream (E-Z-EM, Canada) was administered orally to monitor the location of the esophagus by fluoroscopy throughout the procedure. ${ }^{8}$ After the barium swallow, midazolam and fentanyl were administered for conscious sedation.

\section{Radiofrequency Catheter Ablation}

$\mathrm{AF}$ was induced by atrial pacing in patients who were in sinus rhythm. Radiofrequency catheter ablation was performed with a temperature-controlled, 8-mm-tip ablation catheter (Navistar, Biosense-Webster) in 76 patients and a 3.5$\mathrm{mm}$, irrigated-tip ablation catheter (ThermoCool, BiosenseWebster) in 248 patients. Radiofrequency energy was applied at a maximum temperature of $50^{\circ} \mathrm{C}$ and a maximum power of $70 \mathrm{~W}$ when an 8-mm-tip catheter was used, or a maximum power of $35 \mathrm{~W}$ when an irrigated tip catheter was used. However, the maximum power was reduced to $35 \mathrm{~W}$ or $20-25 \mathrm{~W}$ when ablation was performed around the PV ostia or along the posterior left atrium, with an 8-mm-tip or an irrigated-tip catheter, respectively. Complex fractionated atrial electrograms in the pulmonary veins and their antral areas were targeted for ablation, as described previously. ${ }^{9}$ If $\mathrm{AF}$ persisted or still was inducible in patients with paroxysmal AF, complex fractionated atrial electrograms in the left atrium and coronary sinus were ablated. Ablation was continued until AF terminated and became noninducible (in patients with paroxysmal AF) or until complex, fractionated electrograms were eliminated. ${ }^{9}$

\section{Postablation Care}

After the ablation procedure, all patients were hospitalized overnight and treated with intravenous heparin. Warfarin therapy was restarted the evening of the procedure. Lowmolecular-weight heparin $(0.5 \mathrm{mg} / \mathrm{kg}$ subcutaneously every 12 hours) was used after discharge until the international normalized ratio was $\geq 2.0$. Anticoagulation was continued until patients were free from recurrent $\mathrm{AF}$ and atrial flutter for 3 months after the most recent ablation procedure. 


\section{Follow-Up}

Patients were followed 3 months after the procedure and every 3-6 months thereafter. A 12-lead ECG was obtained during clinic visits. The patients were instructed to contact a nurse if symptoms suggestive of an arrhythmia occurred. A 30-day autotrigger event recorder was provided to patients who remained in normal sinus rhythm at 3-6 months postablation. Because early recurrences of $\mathrm{AF}$ or atrial flutter within the first few weeks after ablation may be transient, ${ }^{10}$ a blanking period of 8 weeks postablation was applied.

The primary endpoint of the study was freedom from recurrent AF in the absence of antiarrhythmic drug therapy after a single ablation procedure. The prevalence of atrial flutter after ablation was also reported.

\section{Statistical Analysis}

Continuous variables are expressed as mean \pm 1 standard deviation and were compared by Student's $t$-test or one-way analysis of variance. Post hoc analyses were performed with the Newman-Keuls test. Categorical variables were compared by Chi-square analysis or Fisher's exact test where appropriate. BMI was analyzed as both a continuous and a categorical variable.

A multivariate logistic regression analysis was performed to determine the independent predictors of recurrent $\mathrm{AF}$ after a single ablation procedure. A $\mathrm{P}<0.05$ indicated statistical significance.

\section{Results}

\section{Radiofrequency Catheter Ablation}

There was no significant difference in the mean duration of the procedure ( $230 \pm 46$ minute vs. $227 \pm 38$ minute, $\mathrm{P}=$ $0.65)$, fluoroscopy $(56 \pm 20$ minute vs. $55 \pm 18$ minute, $\mathrm{P}=$ 0.84 ), and radiofrequency energy application ( $38 \pm 14$ minute vs. $42 \pm 14$ minute, $\mathrm{P}=0.09$ ) between patients without and with OSA.

The mean duration of the fluoroscopy $(\mathrm{P}=0.02)$ and applications of radiofrequency energy $(\mathrm{P}=0.01)$ were longer in obese patients than in normal patients (Fig. 1). However, the mean procedure time was similar.

\section{OSA and Results of Ablation}

The mean duration of follow-up after the first ablation procedure was similar between patients without and with OSA ( $7 \pm 4$ months vs. $7 \pm 4$ months, $\mathrm{P}=0.47$ ). Among the 324 patients with AF, 184 of 292 patients $(63 \%)$ without OSA and 13 of 32 patients (41\%) with OSA were free from AF without antiarrhythmic drug therapy after a single ablation procedure $(\mathrm{P}=0.02)$. Persistent atrial flutter developed in 24 of the 292 patients $(8 \%)$ without OSA and 3 of the 32 patients $(9 \%)$ with OSA $(\mathrm{P}=0.74)$. Overall, 160 of 292 patients $(55 \%)$ without OSA and 10 of 32 patients $(31 \%)$ with OSA were in sinus rhythm without antiarrhythmic drug therapy after a single ablation procedure $(\mathrm{P}=0.01)$. Among 32 patients with OSA, 18 patients were treated with CPAP prior to the ablation procedure. Nine of 18 patients $(50 \%)$ who were on CPAP remained free from $\mathrm{AF}$, whereas 4 of 14 patients $(29 \%)$ with untreated OSA remained free from AF $(\mathrm{P}=0.289)$.

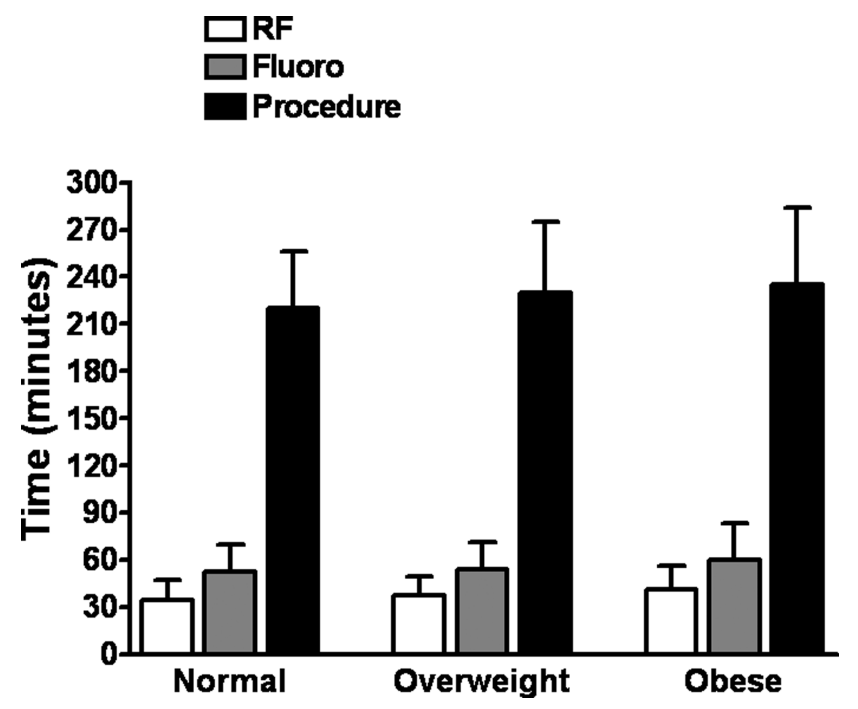

Figure 1. The duration of fluoroscopy, radiofrequency energy applications, and procedure according to BMI. Both the mean duration of fluoroscopy and radiofrequency energy application were longer in obese patients compared to patients with a normal $B M I .{ }^{*} P=0.04$ compared to normal $B M I ;{ }^{\dagger}$ $P=0.007$ compared to normal BMI.

Among the 234 patients with paroxysmal AF, 146 of 211 patients (69\%) without OSA and 11 of 23 patients (48\%) with OSA remained free from $\mathrm{AF}$ after a single procedure $(\mathrm{P}=$ 0.036). Among the 90 patients with chronic AF, 38 of 81 patients $(47 \%)$ without OSA and 2 of 9 patients (22\%) with OSA were free from AF after a single procedure $(\mathrm{P}=0.14)$.

\section{BMI and Recurrence of AF After Catheter Ablation}

As a continuous variable, each one unit increase in BMI was associated with a 5\% increase in the probability of recurrent $\mathrm{AF}$ after a single ablation procedure $(\mathrm{P}=0.01)$. When patients were categorized into three groups according to BMI, overweight and obese patients had a 1.36-fold $(\mathrm{P}=0.38)$ and 2.48 -fold $(\mathrm{P}=0.007)$ increase, respectively, in the probability of recurrent $\mathrm{AF}$, compared with patients with normal weight (Table 4). However, after adjustment for other clinical variables (age, gender, type and duration of AF, left atrial size, and left ventricular ejection fraction), BMI was not predictive of recurrent $\mathrm{AF}(\mathrm{OR}=0.99,95 \% \mathrm{CI}: 0.95-1.04, \mathrm{P}=0.68)$.

TABLE 4

BMI and Recurrence of AF After Catheter Ablation

\begin{tabular}{llll}
\hline & OR & $\mathbf{9 5 \%} \mathbf{C I}$ & $\mathbf{P}$ \\
\hline $\begin{array}{l}\text { Univariate analysis } \\
\text { BMI as a continuous variable }\end{array}$ & 1.05 & $1.01-1.08$ & 0.01 \\
BMI & 1.00 & & \\
$\quad$ Normal & 1.36 & $0.69-2.69$ & 0.38 \\
$\quad$ Overweight & 2.48 & $1.28-4.82$ & 0.007 \\
$\quad \begin{array}{l}\text { Obese } \\
\text { Multivariate analysis }\end{array}$ & 0.99 & $0.95-1.04$ & 0.68 \\
$\quad$ BMI as a continuous variable & & & \\
$\quad$ BMI & 1.00 & & \\
$\quad$ Normal & 1.04 & $0.47-2.36$ & 0.90 \\
$\quad$ Overweight & 1.24 & $0.53-2.90$ & 0.71 \\
$\quad$ Obese &
\end{tabular}

$\mathrm{CI}=$ confidence interval; $\mathrm{OR}=$ odds ratio. 
TABLE 5

Multivariate Analysis of Predictors of Recurrence of AF After Catheter Ablation

\begin{tabular}{lccc}
\hline Variables & OR & $\mathbf{9 5 \%}$ CI & P \\
\hline Age & 1.02 & $0.99-1.05$ & 0.10 \\
Female & 1.23 & $0.65-2.37$ & 0.51 \\
BMI & 0.99 & $0.95-1.04$ & 0.73 \\
Chronic atrial fibrillation & 1.66 & $0.93-2.99$ & 0.09 \\
Duration of atrial fibrillation & 1.03 & $0.99-1.09$ & 0.20 \\
OSA & 3.04 & $1.11-8.32$ & 0.03 \\
Left atrial size & 1.04 & $1.00-1.09$ & 0.08 \\
Left ventricular ejection fraction & 0.97 & $0.94-1.00$ & 0.06 \\
Hypertension & 0.89 & $0.51-1.56$ & 0.67 \\
\hline
\end{tabular}

$\mathrm{CI}=$ confidence interval; $\mathrm{OR}$ = odds ratio.

\section{Multivariate Analysis}

On multivariate analysis, among the variables of age, gender, BMI, type and duration of AF, presence of OSA, left atrial size, left ventricular ejection fraction, and hypertension, OSA was the strongest independent predictor of recurrent $\mathrm{AF}$ after catheter ablation $(\mathrm{OR}=3.04,95 \% \mathrm{CI}: 1.11-8.32, \mathrm{P}=0.03$, Table 5).

\section{Complications}

Among the 324 patients, pericardial tamponade occurred in two patients $(0.6 \%)$ without OSA and was successfully managed by pericardiocentesis. Another patient $(0.3 \%)$ without OSA experienced a transient ischemic attack, which resolved completely within hours. There was no significant difference in BMI among patients who did and did not experience a complication. A major groin hematoma developed in two patients who were overweight and in one patient who had a normal $\mathrm{BMI}(\mathrm{P}=0.48)$.

\section{Discussion}

\section{Main Findings}

The results of this study demonstrate that OSA is associated with a three-fold increase in the probability of recurrent $\mathrm{AF}$ after catheter ablation, independent of comorbidities known to be associated with a higher likelihood of recurrence. In fact, among several covariates, OSA was by far the strongest independent predictor of recurrent $\mathrm{AF}$ after radiofrequency catheter ablation. On the other hand, obesity, although demonstrated to be a risk factor for the development of $\mathrm{AF}$, was not an independent predictor of recurrent $\mathrm{AF}$ after catheter ablation.

\section{Obstructive Sleep Apnea and Atrial Fibrillation}

Previous studies have shown a strong association between OSA and $\mathrm{AF}^{3-5}$ Possible mechanisms by which OSA predisposes to AF include intermittent hypoxemia, hypercapnia, chemoreceptor excitation, and surges in adrenergic tone. ${ }^{11}$ Increases in blood pressure and left ventricular afterload due to sympathetically mediated vasoconstriction during an apneic episode can lead to left atrial enlargement. ${ }^{12}$ Left atrial dilatation and probable fibrosis due to prolonged exposure to elevated left ventricular filling pressures may contribute to the perpetuation of AF. Left atrial stretch has also been demonstrated to promote pulmonary vein arrhythmogenicity.
In this study, OSA was associated with a three-fold increase in the probability of recurrence of AF after radiofrequency catheter ablation. Although patients with OSA are more likely to have comorbid conditions that predispose to $\mathrm{AF}$, such as larger left atrial size, lower ejection fraction, higher BMI, and hypertension, OSA was the only independent predictor of recurrences of AF by multivariate analysis. The explanation for the lower efficacy of catheter ablation of $\mathrm{AF}$ in patients with OSA is unclear, but it is possible that ongoing hypoxemia, hypercapnia, surges in sympathetic tone, and left atrial stretch cause the emergence of previously untargeted sites that initiate and/or maintain AF.

Patients with untreated OSA were found to have a higher incidence of recurrent $\mathrm{AF}$ after cardioversion than patients with treated OSA or patients without OSA. ${ }^{3}$ In this study, the sample sizes were not large enough to discern accurately whether treatment with CPAP mitigated the effects of OSA on the outcome of radiofrequency catheter ablation of AF.

\section{Body Mass Index}

Obesity was found to be a modifiable risk factor for $\mathrm{AF}$ in a large, community-based cohort study. ${ }^{1}$ Because there is strong correlation between BMI and left atrial size, ${ }^{13}$ the effect of obesity may be mediated by left atrial distension. ${ }^{14}$ Left atrial enlargement may result from elevated plasma volume, ${ }^{15}$ ventricular diastolic dysfunction, ${ }^{16}$ and enhanced neurohormonal activation ${ }^{17}$ in overweight and obese patients. Furthermore, autonomic dysfunction ${ }^{18}$ and sleep apnea ${ }^{3}$ may further facilitate $\mathrm{AF}$ in obesity.

Despite the association between obesity and AF, the BMI was not related independently to the risk of recurrent $\mathrm{AF}$ after catheter ablation in this study. It may be that comorbid conditions such as sleep apnea or left atrial enlargement are the key variables that promote $\mathrm{AF}$ in overweight and obese patients. Obesity may simply be a phenotypic marker of profibrillatory comorbidities.

The longer fluoroscopy time and duration of radiofrequency energy applications in obese than in normal patients may be due to larger left atrial size that necessitates more extensive ablation.

Of note is that $>80 \%$ of patients in this study were either overweight or obese. In contrast, the prevalence of a BMI $\geq 25$ in the adult population in Michigan is $61 \%$ (CDC, 2005). It is possible that patients with a high BMI are more likely to have $\mathrm{AF}$ and therefore are more often referred for an ablation procedure. Nevertheless, the high prevalence of elevated BMI points to the obesity pandemic and underscores the need for early measures to prevent and treat obesity.

\section{Limitations}

The principal limitation of this study is that not all patients underwent polysomnography. Therefore, the prevalence of OSA may have been underestimated.

The findings of this study may be valid only for the specific type of ablation strategy employed. However, the ablation strategy utilized in this study has been reported to have comparable efficacy to other commonly used ablation techniques. ${ }^{9}$

Because the number of patients receiving therapy with CPAP was small, the study did not have adequate power to determine the effect of CPAP on the efficacy of catheter ablation in patients with OSA. 


\section{Conclusions}

Patients with OSA are less likely to remain in sinus rhythm after radiofrequency catheter ablation for AF. It remains to be determined whether aggressive management of OSA will result in improvement in clinical efficacy of catheter ablation for AF.

Although BMI is not an independent predictor of recurrent $\mathrm{AF}$ after radiofrequency catheter ablation, BMI is causally linked to OSA and other variables, such as left atrial enlargement, which promote AF. It also remains to be determined whether weight reduction will decrease the heightened risk of AF associated with obesity.

\section{References}

1. Wang TJ, Parise H, Levy D, D’Agostino RB Sr, Wolf PA, Vasan RS, Benjamin EJ: Obesity and the risk of new-onset atrial fibrillation. JAMA 2004;292:2471-2477.

2. Young T, Skatrud J, Peppard PE: Risk factors for obstructive sleep apnea in adults. JAMA 2004;291:2013-2016.

3. Kanagala R, Murali NS, Friedman PA, Ammash NM, Gersh BJ, Ballman KV, Shamsuzzaman AS, Somers VK: Obstructive sleep apnea and the recurrence of atrial fibrillation. Circulation 2003;107:2589-2594.

4. Somers VK: Sleep-a new cardiovascular frontier. N Engl J Med 2005;353:2070-2073.

5. Yaggi HK, Concato J, Kernan WN, Lichtman JH, Brass LM, Mohsenin $\mathrm{V}$ : Obstructive sleep apnea as a risk factor for stroke and death. N Engl J Med 2005;353:2034-2041.

6. Sleep-related breathing disorders in adults: Recommendations for syndrome definition and measurement techniques in clinical research. The Report of an American academy of sleep medicine task force. Sleep 1999;22:667-689.

7. Executive summary of the clinical guidelines on the identification, evaluation, and treatment of overweight and obesity in adults. Arch Intern Med 1998;158:1855-1867.
8. Good E, Oral H, Lemola K, Han J, Tamirisa K, Igic P, Elmouchi D, Tschopp D, Reich S, Chugh A, Bogun F, Pelosi F Jr, Morady F: Movement of the esophagus during left atrial catheter ablation for atrial fibrillation. J Am Coll Cardiol 2005;46:2107-2110.

9. Oral H, Chugh A, Good E, Sankaran S, Reich SS, Igic P, Elmouchi D, Tschopp D, Crawford T, Dey S, Wimmer A, Lemola K, Jongnarangsin K, Bogun F, Pelosi F Jr, Morady F: A tailored approach to catheter ablation of paroxysmal atrial fibrillation. Circulation 2006;113:18241831.

10. Oral H, Knight BP, Ozaydin M, Tada H, Chugh A, Hassan S, Scharf C, Lai SW, Greenstein R, Pelosi F Jr, Strickberger SA, Morady F: Clinical significance of early recurrences of atrial fibrillation after pulmonary vein isolation. J Am Coll Cardiol 2002;40:100-104.

11. Somers VK, Dyken ME, Clary MP, Abboud FM: Sympathetic neural mechanisms in obstructive sleep apnea. J Clin Invest 1995;96:18971904.

12. Somers VK, Mark AL, Zavala DC, Abboud FM: Influence of ventilation and hypocapnia on sympathetic nerve responses to hypoxia in normal humans. J Appl Physiol 1989;67:2095-2100.

13. Pritchett AM, Jacobsen SJ, Mahoney DW, Rodeheffer RJ, Bailey KR, Redfield MM: Left atrial volume as an index of left atrial size: A population-based study. J Am Coll Cardiol 2003;41:1036-1043.

14. Vaziri SM, Larson MG, Benjamin EJ, Levy D: Echocardiographic predictors of nonrheumatic atrial fibrillation. The Framingham Heart Study. Circulation 1994;89:724-730.

15. Messerli FH, Ventura HO, Reisin E, Dreslinski GR, Dunn FG, MacPhee AA, Frohlich ED: Borderline hypertension and obesity: Two prehypertensive states with elevated cardiac output. Circulation 1982;66:5560 .

16. Iacobellis G, Ribaudo MC, Leto G, Zappaterreno A, Vecci E, Di Mario U, Leonetti F: Influence of excess fat on cardiac morphology and function: Study in uncomplicated obesity. Obes Res 2002;10:767773.

17. Engeli S, Sharma AM: The renin-angiotensin system and natriuretic peptides in obesity-associated hypertension. J Mol Med 2001;79:2129.

18. Pelat M, Verwaerde P, Merial C, Galitzky J, Berlan M, Montastruc JL, Senard JM: Impaired atrial M(2)-cholinoceptor function in obesityrelated hypertension. Hypertension 1999;34:1066-1072. 